\title{
On the Character of Georgian Verse
}

\section{Tamar Lomidze*}

\begin{abstract}
Research on the character of Georgian verse started in 1731. Since that time, some researchers have described Georgian verse as syllabic, while others have said that it is syllabotonic. The dispute about the character of Georgian verse became particularly acute in the 20th century. The main text the participants in the dispute analysed was a prominent piece of Georgian poetry of the 12th century - The Knight in the Panther's Skin by Shota Rustaveli. It consists of 16-syllable monorhymical quatrains that have a special name in Georgian - shairi. There are two varieties of shairi - the

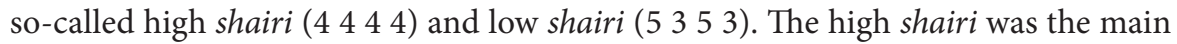
issue of the dispute. The researchers who regarded Georgian verse as belonging to the syllabotonic system divided high shairi into trochaic feet, while the supporters of the syllabic theory denied the presence of metric trochaic stress in high shairi, believing that the penultimate syllables can be stressed only in two-syllable words but not in words with multiple syllables (due to the dactylic accentuation typical in the modern Georgian language).

Since natural dactylic stress (found in low shairi) reflects the accentuation norms of the language of the later period (including those of modern Georgian), we assume that metric stress in high shairi, which is no longer found in modern Georgian speech, could be a reflection of the natural accentuation of the comparatively earlier period in the development of the Georgian language. Checking this hypothesis by relying on relevant linguistic literature, we reconstructed the archaic movable and phonologically relevant stress in the rhymed words in The Knight in the Panther's Skin. We found that metric stresses of both high and low shairi in this epic poem are actually archaic linguistic stresses. This conclusion differs from the views expressed in concepts developed earlier. It enables us to take a fresh look at the metrics and rhymes of The Knight in the Panther's Skin as well as the main principles and specific features of Georgian verse in general.
\end{abstract}

Keywords: versification, metric accentuation, syllabotonic verse, shairi

The history of Georgian verse is quite long. The most recent research (Silagadze 1997) confirmed the earlier assumption that in Georgia in the pre-Christian era (before the 4th century AD), there was "old secular literature, which had such powerful traditions and deep roots that Christian literature introduced

* Author's address: Tamar Lomidze, School of Arts and Sciences, Ilia State University, Kakutsa Cholokashvili Ave 3/5, Tbilisi 0162, Georgia. Email: tamar_lomidze@iliauni.edu.ge. 
later failed to eradicate it and completely hinder its development" (Ingorokva 1938: 6). Georgian literary texts of that era are not extant.

Ancient examples of Georgian poetry (starting from the 7th century AD; Kekelidze 1951: 559) consist of numerous translated (from Greek) and original ecclesiastic texts that belong to the syllabic system in terms of versification. They are verses written in the so-called form of iambico and "an imitation of a non-Georgian phenomenon"1 (Silagadze 1997: 44). Iambico is a poem in five lines, each containing 12 syllables with caesuras after the fifth syllable.

Secular poetry started to develop in Georgia from the 11th and 12th centuries. The new literary Georgian language took shape in the same period, while Old Georgian was used only in ecclesiastic literature (Gigineishvili 1952: 502; Chikobava 1952: 364).

Laudatory poems such as Tamariani by Chakhrukhadze and Abdulmesiani by Ioane Shavteli were written in the new language in this period. The Knight in the Panther's Skin by Shota Rustaveli was also written in the 12th century. It has been recognised as an unmatched benchmark example of Georgian poetry. The versification of The Knight in the Panther's Skin ${ }^{2}$ was regarded as mandatory for Georgian poems until the 18th century. When speaking about the nature of Georgian verse, researchers necessarily analysed the specific features of the versification of this epic poem.

Researchers have expressed different views about Georgian verse over the past three centuries since research on the topic started in 1731. Some thought that Georgian verse is syllabic and others believed that it is syllabotonic. The dispute about the character of Georgian verse became particularly acute in the 20th century. The prominent scientists Akaki Gatserelia and Giorgi Tsereteli were the major participants in the dispute.

Why did this dispute continue for such a long time? Why is dual interpretation of Georgian verse possible? Why can it be regarded as syllabic on the one hand and syllabotonic on the other? The supporters of the syllabic theory probably relied on the weakness of stress and how it is devoid of phonological

1 Byzantine spiritual literature.

2 The Knight in the Panther's Skin consists of 16-syllable monorhymical quatrains (the only exception is one 20-syllable quatrain) that have a special name in Georgian - shairi. Each stanza has four rhymed words in the clausulas. The rhyme is exact, that is, the stressed vowels and the syllables in the clausulas are always completely identical. Silagadze notes that shairi is an Arabic word, but "in Arabic, this word is not a term related to versification. What is most important, Arabic-language verse lines have no forms (metres and so forth), which would be similar with the Georgian form at least to a certain extent" (Silagadze 2018: 11). The so-called high shairi (4 444 ) and low shairi (5 353 ) are varieties of shairi. 
value in Georgian. In addition, isosyllabism was characteristic of Georgian verse in its classical period (until the 18th century), which was yet another proof for the followers of the syllabic theory.

However, the Georgian stress, which is almost inaudible in speech, becomes stronger in verses (Gatserelia 1953: 133). Based on this, the supporters of the syllabotonic theory maintained that, in addition to the equal number of syllables in every line, stress also plays an essential role in Georgian verse, which is typical for syllabotonic versification.

However, researchers admitted that stress in Georgian words is weak; therefore, it is difficult to find a stressed syllable in a word. They nevertheless attempted to establish its place in words. In particular, some scholars assert that the penultimate syllable is stressed in two-syllable words and the third from the last syllable in words with three and more syllables; they include Nikolai Marr, Giorgi Akhvlediani, Sergi Zhghenti, Giorgi Tsereteli, Izabella Tevdoradze, Akaki Gatserelia, and Togo Gudava. In this sense, "the Georgian stress is fixed, but it cannot be regarded as a typical fixed stress" (Gatserelia 1953: 134).

The same researchers believe that Georgian stress is movable, as it changes places if the number of syllables and grammatical forms change.

$$
\begin{aligned}
& \text { m'argalits - dative singular; } \\
& \text { marg' } \text { aliti }^{3} \text { - nominative singular; } \\
& \text { margal'itebi - nominative plural (Gatserelia 1953: 123). }
\end{aligned}
$$

Thus, "the Georgian language is dactylic and this principle is the spine of our speech" (Gatserelia 1953: 123).

Akaki Gatserelia asserts that Georgian verse belongs to the syllabotonic system of versification. He distinguishes between dactylic and trochaic feet in Georgian verses. For example, he presents the following structure of the high shairi in The Knight in the Panther's Skin:

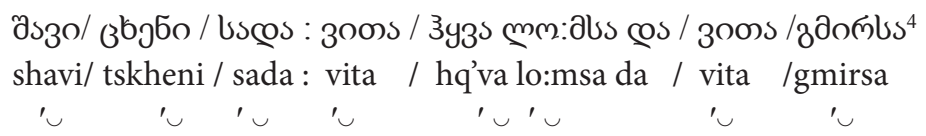

\footnotetext{
3 Margaliti - a pearl in Georgian.

4 Slashes mark the end of feet when they coincide with word boundaries, and colons are used when there is no such coincidence.
} 
Low shairi consists of trochees and dactyls:

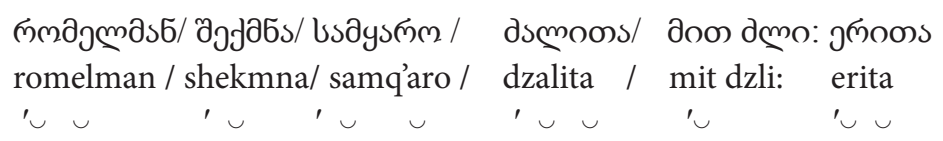

Gatserelia's monograph Georgian classical verse (1953) had a significant impact on the development of the study of Georgian verse.

In 1973, Giorgi Tsereteli published "The Metre and Rhyme in The Knight in the Panther's Skin". He regards Georgian verse as syllabic. He calls the half line of high shairi symmetrical (4 4) and the half line of low shairi (5 3 or 35 ) asymmetrical.

According to Tsereteli, lines in The Knight in the Panther's Skin are divided into segments, ${ }^{5}$ not feet. In his view, it is inadmissible to divide high shairi into trochaic feet: "All native speakers of Georgian can feel that such a distribution of stresses in words is unnatural and unacceptable for their language. [...] A stress on the penultimate syllable is admissible in two-syllable words [...] but not in invented fictitious 'feet' that are part of four-syllable segments" (Tsereteli 1973: 24-25). In other words, since the metric stresses of high shairi do not correspond to the dactylic accents of the modern Georgian language, Tsereteli rejected the opinion that Georgian verse is syllabotonic.

Tsereteli did not criticise the metric accentuation of low shairi because such (dactylic) stress is characteristic of modern Georgian. ${ }^{6}$ In his view, no specific poetical stresses appear in Georgian verse, and the only factor that is decisive is the isosyllabism of verse lines. He explains that "stress is fixed and falls on the penultimate syllables in two-syllable words, the third syllable from the end in three-syllable and in four-syllable words. However, according to some studies, the third and fourth syllables are pronounced with the same stresses. According to the same data, the third, fourth, and fifth syllables also bear the same stresses in five-syllable words" (Tsereteli 1973: 38).

According to Giorgi Tsereteli, the number of stresses in a line of a poem is equal to the number of words. This opinion makes it clear that he did not regard poetical and prosaic speech as different from each other in prosodic terms, at

\footnotetext{
5 He implies segments of a poem's lines between caesuras, for example, segments of high shairi - 4444 - and low shairi - 5353 .

${ }_{6}$ It should also be noted that in Tsereteli's opinion, the so-called principle of section aurea is embodied in low shairi because the small segment (3) in its half line is in the same correlation with the big segment (5) as the big segment (5) is correlated with the whole (8) (Tsereteli 1973: 14).
} 
any rate. ${ }^{7}$ He did not take into account that language and verse are two different systems, although it is true that language is the foundation of verse.

Tsereteli also examined rhymes in The Knight in the Panther's Skin and noted that "since two-syllable words in Georgian tend to have a stress on the penultimate syllable and the number of rhymes made of two-syllable words is almost $40 \%$ (39.8\%), one gets the impression that rhymes in high shairi are 'trochaic'. However, this is a 'trochaic trend', not the structural foundation of verse" (Tsereteli 1973: 58). Similarly, "since three-syllable words usually bear the stress on the third last syllable, one gets the impression at the level of intuition here too that the rhymes in low shairi are 'dactylic' [...]. The endings of lines in low shairi accidentally become similar to 'dactylic rhymes', creating the 'dactylic trend', but essentially [...] this is no dactyl' (Tsereteli 1973: 62).

A little later, Arabic specialist Apolon Silagadze shaped a completely different theory. He produced a convincing substantiation, showing that Georgian verse does not belong to any known system of versification. In general, it is not the syllabic or syllabotonic nature of Georgian verse that determines its specific features but a universal principle, characteristic of Georgian verse at all stages of its development. This principle is the so-called principle of binary section. ${ }^{8}$

In Georgian verse, Apolon Silagadze singles out the smallest units called segments. For example, low shairi consists of four segments: $5+3+5+3$, but neither 5 nor 3 are rhythmically independent units. (It is not enough to say that a 5-complex segment occurs in low shairi. It should be pointed out that low shairi consists of the $5+3+5+3$ sequence of segments). A segment is a non-binary and non-rhythmic unit that builds a superior rhythmic and binary unit (binomial), but itself does not have a binary structure.

Silagadze formulates the following rule of verse segmentation: the smallest rhythmic unit should be considered an element of a verse line that can build a complete rhythmic unit. Such a rhythmic element is a binomial, which can construct a line, a double verse and a stanza. Each of them has a binary structure.

The structural rules for these rhythmic units are follows:

1. Units have a binary structure: $\mathrm{n}+\mathrm{k}$.

2. The second component should not be longer than the first: $\mathrm{n} \geq \mathrm{k}$.

\footnotetext{
$7 \quad$ "Poetical and speech readings do not exist separately. They coincide with each other," according to another researcher in Georgian verse, Akaki Khintibidze. He was a supporter of Tsereteli's theory (Khintibidze 366).

8 The size of this paper makes it impossible to describe this extremely interesting theory, which offers an effectively exhaustive analysis of the specific features of Georgian verse.
} 
3. Each binomial has a main variant and an alternant, in which the rhythmic boundary is moved back to the left by two syllables:

$\mathrm{n}+\mathrm{k} \Leftrightarrow(\mathrm{n}-2)+(\mathrm{k}+2)$,

where $\mathrm{n} \geq \mathrm{k}$,

$\mathrm{n}=3,4,5 ; \quad \mathrm{k}=0,1,2,3,4,5$.

For example, in low shairi there are binomials: $5+3$ and $3+5$.

In general, the binary rhythmic units of Georgian verse have the following structural characteristics: 1 . rhythmic boundary; 2. length; 3 . configuration of stresses. Of these, the main structural factor is the rhythmic boundary, which emerges between the two components of the rhythmic units of all levels (binomial, line, double verse, stanza) (Silagadze 1987).

Of course, Silagadze took into account the discussions under way in the second half of the 20th century between Gatserelia and Tsereteli that were aimed at clarifying the nature of Georgian verse. Silagadze did not deny the existence of the "organised distribution of rhythmic stresses"9 in Georgian verse but noted that such a distribution of stresses is a "concomitant sign, not structural (rhyme-creating)" (Silagadze 1987: 127). At the same time, according to Silagadze, the "distribution of stresses has a local and auxiliary function that is materialised in certain conditions" (Silagadze 1987: 129).

It should be noted here that unlike Apolon Silagadze, who analysed all stages of the development of Georgian verse (from the 7th to 20th century), Akaki Gatserelia attempted to determine the nature of Georgian verse on the basis of examining the stage of its development in the period, when it was characterised by the "organised distribution of rhythmic stresses". As regards Tsereteli, he analysed only The Knight in the Panther's Skin. Both scholars wrongly believed that their conclusions reflected the nature of Georgian verse in general.

In the current study, we attempted to clarify the problem of the nature of Georgian verse in the context in which Gatserelia and Tsereteli examined it. In particular, we examined the correlation of metric and natural stresses in The Knight in the Panther's Skin and its rhymed words in particular. ${ }^{10}$ Of course, we had a special focus on high shairi.

9 Specific features of syllabotonic verse are implied here.

10 We analysed only the rhyme words in The Knight in the Panther's Skin because it is technically very difficult to analyse the whole text of the poem. In addition, even Gatserelia did not call into question the place of stresses in rhyme words. 
What is the origin of the trochaic stress that can be found only in verses (high shairi)? Why does dactylic stress that is barely felt in the standard Georgian language become stronger in low shairi? It is admissible to presume that the stress existed as a linguistic stress extant in the shape of metric stress in east Georgian folkloric verse ${ }^{11}$ (which uses low shairi) on the one hand and on the other in west Georgian, specifically Megrelian verse, which uses only high shairi. ${ }^{12}$ As mentioned above, The Knight in the Panther's Skin uses both types of shairi.

The question was often asked whether the alternation of different kinds of shairi in The Knight in the Panther's Skin could be due to some special reason. For example, "references were made to slowing down or speeding up the tempo (the former in low shairi and the latter in high shairi), evasion of rhythmic monotony, and sometimes the factor of the content" (Khintibidze 2009: 148). We express below a different theory on reasons for the use of both high and low shairi in The Knight in the Panther's Skin.

Clausulas in the rhyming words of low shairi consist of three syllables, and they are dactylic. Correspondingly, metric accents in these words coincide with modern natural accents because it is believed that stress is dactylic in the words that consist of three or more syllables; i.e., it falls on the third from the last syllable.

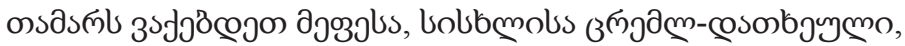

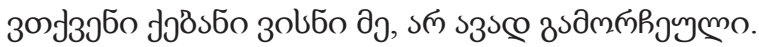

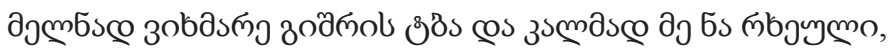

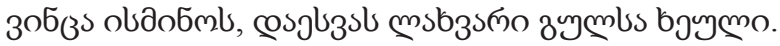

'tamars 'vakebdet 'mepesa, 'siskhlisa 'tsreml-datkh' euli,

'vtkveni 'kebani 'visni me, 'ar avad 'gamorch'euli.

'melnad 'vikhmare 'gishris t'ba 'da kalmad 'me na rkh'euli,

'vintsa 'isminos, 'daesvas 'lakhvari 'gulsa kh' euli.

By shedding tears of blood we praise our King and I'll say at the start:

I think myself far from the least of those who've played a praising part.

A lake of ebony I used as ink, my reed was like a dart.

Whoever hears the lines I have written, a spear will pierce his heart! ${ }^{13}$

11 The standard Georgian language took shape on its basis.

12 Compare Silagadze 2014.

13 Translated by Lyn Coffin. 
The situation is different in high shairi, in which clausulas are trochaic and consist of two syllables. In such words, metric trochaic stresses in multi-syllable words do not coincide with the dactylic stresses characteristic of the Modern Georgian language (which, as we know, Giorgi Tsereteli found very surprising).

Let us look at a strophe from The Knight in the Panther's Skin:

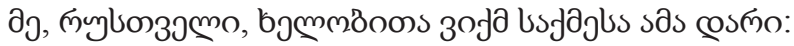

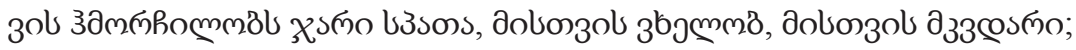

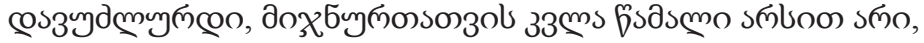

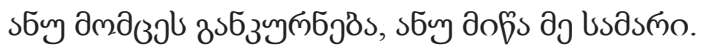

'me, rustv' eli kh'elob'ita, 'vikm sakm'esa 'ama d'ari:

'vis hmorch'ilobs 'jari 'sp'ata, 'mistvis 'vkhelob, 'mistvis mk'vd'ari;

'davudzl'urdi, 'mijnurt'atvis 'k'vla ts'am'ali 'arsit 'ari,

'anu 'momtses 'gank'urn'eba, 'anu 'mits'a 'me sam'ari.

I, Rustaveli, did this deed half-crazed by the presence I crave.

The ruler whom whole armies obey is the reason that I rave.

No cure or remedy exists for the illness my loving gave:

The one I love must ease my pain, or this earth will soon be my grave. ${ }^{14}$

It is necessary to note the difference between the metric stresses of high and low shairi compared to the stresses in the modern language: The metric stresses are on every second syllable in high shairi, ${ }^{15}$ while the metric stresses in low shairi coincide with the natural accentuation of the modern Georgian language.

If the natural dactylic stress (found in low shairi) reflects the more recent norms of accentuation in the Georgian language (although, as said above, they are almost inaudible in ordinary speech), it is possible to presume that the metric stress in high shairi, which is no longer audible in modern Georgian speech, can correspond to the natural accentuation in the Georgian language in an earlier period.

\footnotetext{
14 Translated by Lyn Coffin.

15 This is characteristic of Megrelian verse (Megrelian is one of the Kartvelian languages). In addition, research has confirmed that Megrelian verse "reflects the most ancient stage [...] of the development of Georgian verse" (Silagadze 2014: 116).
} 
Arnold Chikobava noted that Old Georgian shows significant differences from modern Georgian speech in the distribution of stresses. In his opinion:

1. Both the last and first (second or third from the end) syllables could be stressed in Old Georgian.

2. The stress was intensive and dynamic.

3. The stress was not fixed, it was movable.

4. The loss of vowels was intrinsically linked to the stress. (Chikobava 1942: 298)

In addition, "the contraction of word stems under the influence of the vowel in suffixes was usual for Georgian: The historical implication of the phenomenon is probably linked to the fact that the relevant suffix bore the stress.

"mkhevl-' is-a, megobr-'is-a, masts'avlebl-' is-a should have followed the model of dzm-'is-a (dzma is the stem - T.L.), dgh-' is-a (dghe is the stem T.L.), dzvl-'is-a (dzvali is the stem - T.L.)" (Chikobava 1942: 196).

Modern Georgians, who observe dactylic accentuation when speaking, read the examples used by Chikobava in the following manner: mkh'evl-is-a, meg'obr-is-a, masts'avl'ebl-is-a.

Movable and dynamic stress that has a phonological value is supposed to have been characteristic not only for the Old Georgian language (before the 11 th and 12th centuries), but also at much earlier stages of development. It was characteristic of the Proto-Kartvelian language. This linguistic phenomenon is a postulate of the monograph by Tamaz Gamkrelidze and Givi Machavariani System of Sonants and Ablaut in Kartvelian Languages: "Admitting the existence at an early stage of the development of common Kartvelian of movable dynamic stress, which led to the weakening and loss of unstressed vowels can be one of the explanations of the possible reasons for the syncopation of vowels [...] stress [...] had a phonological value" (Gamkrelidze, Machavariani 1965: 370).

The same authors note that the forms of Georgian verbs differed in various vocalisations of verbal stems and suffixes. If a verbal stem was pleophonic, it was followed by a zero-vowel suffix (CVC-C) and vice versa, zero-vowel stems were always followed by pleophinic suffixes (CC-VC) (Gamkrelidze, Machavariani 1965: 183). Taking into account the opinions of these authors and Arnold Chikobava, the stress was to fall on verbal stems in the first case 
and on suffixes in the second case, "which led to the weakening and loss of unstressed vowels". ${ }^{16}$

Sometimes, verbal stems had long vowels. "The most important structural feature of this type of verbs was that in aorist, stems did not move to the zero (reduced) grade of vocalisation, although the pleophonic e suffix followed them" (Gamkrelidze, Machavariani 1965: 240). We think it would be correct to presume that the verbs of this group would retain the stress on the stem. For example, the same authors said that in aorist, ${ }^{17}$ the -en suffix of the direct object (or subject) in plural led to the syncopation of vowels in stems: v-k'al'en $\rightarrow$ v-k'l-'en ("I killed them"), which is a CC-VC form.

Indeed, we find such verbs in the rhyming words of The Knight in the Panther's Skin: gardav-vl-'en-i-t, mov-k'l- 'en-i-t, moa-skh-'en-i-t, movert'q' ' en-i-t, gave-khrml-' en-i-t, shevh-k'ivl- 'en-i-t, where metric stress falls on the same place as archaic stress. ${ }^{18}$ In the poem, we also find a rhyming word da-khots-en-i-t, where the vowel in the stem is not lost, but according to the authors of System of Sonants, because the vowel is long (Gamkrelidze, Machavariani 1965: 245), it is not syncopated.

In the text of the poem, we also find words with the zero-vowel -en suffix and the pleophonic verbal stems. Correspondingly, metric (trochaic) stress falls on the stems. Presumably, archaic natural stress also fell on the stems: gaa-d 'id-n-es, dah-r' id-n-es, aa-chk' ar-n-es, and m-i-kh' ots-n-es, amo-gv-ts'q'v'id-n-es, migv-i-q'v'an-n-es, da-gva-gv'an-n-es, she-i-q' arn-es, ts'a-i-k' 'id-n-es, e-taq'v'an-n-es, mo-e-khv'iv-n-es, mi-e-g' $\mathbf{e b - n - e s , ~}$ ga-a-mq' 'ar-n-a, da-a-ts'q'n 'ar-n-a, mi-u-q' ar-n-a, she-u-khv'iv-n-a, a-t'k'iv-n-a, shemo-st' 'ir-n-a, da-gv-i-dzv'ir-n-a, da-gv-i-ch' 'ir-n-a...

Low shairi also shows coincidence of metric (dactylic) and archaic natural stresses in the forms of aorist. Although verbal stems and suffixes in cases, where the -en suffix is found in rhyming words, seem to be fully voiced, the vowels in the stems of these verbs were long (Gamkrelidze, Machavariani 1965: 240-262), so they were not syncopated, for example:

16 Sometimes, verbal stems had long vowels. "The most important structural feature of this type of verbs was that in aorist, stems did not move to the zero (reduced) grade of vocalisation, although the pleophonic $e$ suffix followed them" (Gamkrelidze, Machavariani 1965: 240). We think it would be correct to presume that the verbs of this group would retain the stress on the stem.

17 Interestingly, forms of aorist are most frequent in verbs used as rhyming words in high shairi.

18 It may seem that the $i$ vowel in the last syllable contradicts our opinion. However, it should be born in mind that kivil-is the stem in the verbal form of shevh-kivl-'en-it. 
mo-i-j'ar-en-i-t, ga-v-i-kh' ar-en-i-t, she-v-i-q' 'ar-en-i-t, mo-i-gv'ar-en-i-t, ga-v-i-ts 'ad-en-i-t, da-v-e-r' ${ }^{\prime}$ dd-en-i-t, da-v-i-b 'ad-en-i-t, da-e-mz' ad-en-i-t, shemo-m-gv'ar-en-i-t, ga-v-i-zr'akh-en-i-t, and so forth.

Aorist is an ancient verbal form in Georgian and it is not surprising that archaic forms of accentuation can be extant in both high and low shairi. We will not quote other verbal forms here that are used in high and low shairi. This requires a vast linguistic analysis since the verbal forms are highly varied. That analysis can be found in our monograph, Georgian verse: Structure and semantics (2021). In addition, we believe that the analysis of the aorist verbal forms is quite convincing in this paper.

In general, the conclusions drawn from the analysis of accentuation peculiarities of The Knight in the Panther's Skin are as follows. High shairi always shows coincidence of metric and archaic natural stresses in verbal forms. The same is often true for masdars and participles. These stresses mostly fall on different syllables in nouns (Lomidze 2021). In low shairi, metric and natural stresses coincide in the verbal forms of aorist and the present tense and often in masdars and participles. They do not coincide in nouns (ibid.). ${ }^{19}$ Modern standard Georgian retains dactylic accentuation, but as is known, the stress has lost its phonological value and is very weak.

It is noteworthy that the adepts of both the syllabotonic and syllabic theories were fully aware of the fact that the old and modern Georgian accentuations were different. For example, Gatserelia noted: "The opinion has been expressed in special linguistic literature that stress could be movable in Old Georgian. This issue is important in terms of studying Georgian stress historically [...]. At the time, when syllabotonic verse emerged and developed, stress was already fixed in the standard Georgian language. Georgian syllabotonic verse found word stress falling on the same place it falls now" (Gatserelia 1953: 112). Gatserelia defended this position to the end, although dactylic stresses of the modern Georgian language cannot be found in high shairi with its trochaic feet.

As regards Giorgi Tsereteli, he was the author of the foreword to System of Sonants by Tamaz Gamkrelidze and Givi Machavariani. He was familiar with the authors' opinion on archaic Georgian stress and indicated this in his own book when he referred to "the Georgian language proper, not ProtoKartvelian, which some researchers presume to be different" (Tsereteli 1973: 106). However, he seems not to be familiar (or not to agree) with Chikobava's

19 It should be taken into account that the most ancient extant copy of The Knight in the Panther's Skin is of the 16th century. It is not ruled out that scribes changed some words in the text of the poem during the four centuries. 
works, which say that archaic movable Georgian stress that had a phonological value retained its features not only in Proto-Kartvelian, but also later, in the old Georgian language.

At any rate, neither Gatserelia nor Tsereteli presumed that the specific features of high shairi in The Knight in the Panther's Skin could have been due to the use of archaic stress.

It is also important that for a couple of exceptions, there are no cases in The Knight in the Panther's Skin in which the same lexical unit is used in the same grammatical form as a rhyming word in high or low shairi bearing different metrical stresses - trochaic in one case and dactylic in another. In our opinion, this is yet another proof in favour of the hypothesis, which says that in Rustaveli's poem, metric accentuation mostly coincides with natural or archaic accentuation (characteristic of high shairi) or more recent accentuation characteristic of low shairi. However, the analysis we carried out has shown that dactylic stresses of low shairi also coincide with archaic stresses, and they cannot be regarded as fixed stresses in the sense in which this term is used regarding the modern Georgian language.

What conclusions can be drawn from the aforesaid?

Let us recall that in Giorgi Tsereteli's opinion, The Knight in the Panther's Skin is an example of syllabic verse. This opinion does not seem to go contrary to our conclusions, because metric stresses (in high and low shairi) are indeed linguistic stresses in words. Thus, Tsereteli's theory seems to be confirmed. However, Tsereteli could not see any difference between the accentuations of high and low shairi. He believed that high shairi did not differ from low shairi in terms of accentuation.

The conclusions we drew is only in partial harmony with Gatserelia's theory. This theory says that the versification of The Knight in the Panther's Skin is syllabotonic and is characterised by specific verse stresses. Gatserelia did not presume that the so-called syllabotonic metric stress could be archaic natural stress, but the principle of division of high shairi lines in The Knight in the Panther's Skin (on the basis of "metric trochaic stress" according to Gatserelia's theory and on the basis of natural archaic stress according to our research) is correct in Gatserelia's theory.

Thus, we conclude that neither Akaki Gatserelia's nor Giorgi Tsereteli's theories can clarify the specific features of the development of Georgian verse in the period when it was characterised by the "organised distribution of stresses" that is "actualised in certain conditions" (Silagadze 1987: 128). Our conclusions do not contradict Apolon Silagadze's theory. This auxiliary function seems to have been not so insignificant since the "certain conditions" continued for centuries and played an essential role in the history of Georgian verse. 


\section{References}

Chikobava, Arnold 1942. Makhvilis sak'itkhisatvis dzvel kartulshi. In: Sakartvelos SSR metsnierebata ak'ademiis moambe 3(3), 296-303.

Chikobava, Arnold 1952. Enatmetsnierebis shesavali. Tbilisi: Tbilisis universit'et'is gamomtsemloba.

Gamq'relidze, Tamaz; Mach'avariani, Givi 1965. Sonant'ta sist'ema da ablaut'i kartvelur enebshi. Tbilisi: Metsniereba.

Gats'erelia, Ak’ak'i 1953. Kartuli k'lasik'uri leksi. Tbilisi: Sabch'ota mts'erali.

Gigineishvili, Ivane 1952. Ertiani kartuli salit'erat'uro enis sak'itkhebi. In: Iberiulk'avk'asiuri enatmetsniereba III. Tbilisi: Georgian Academy of Sciences Press, 500-514.

Ingoroq'va, Pavle 1938. Rustavelis ep’okis salit'erat'uro memk'vidreoba. In: Rustavelis saiubileo k'rebuli. Tbilisi: Sakhelgami, 4-46.

K'ek'elidze, K'orneli 1951. Dzveli kartuli lit'erat'uris ist'oria. Tbilisi: Tbilisis universit'et'is gamomtsemloba.

Khintibidze, Ak'ak'i 2009. Kartuli leksis ist'oria da teoria. Tbilisi: Tbilisis univerisit'et'is gamomtsemloba.

Lomidze, Tamar, 2021 Kartuli leksi: st'rukt'ura da semant'ik'a. Tbilisi: Shota Rustavelis sakhelobis kartuli lit'erat'uris inst'it'ut'i.

Silagadze, Ap’olon 1987. Leksmtsodneobiti analizis p’rintsip’ebis shesakheb. Tbilisi: Tbilisis universit'et'is gamomtsemloba.

Silagadze, Ap’olon 1997. Dzveli kartuli leksi da kartuli p’oeziis udzvelesi sapekhuris p'roblema. Tbilisi: Tbilisis universit'et' is gamomtsemloba.

Silagadze, Ap’olon 2014. Megruli leksi. Tbilisi: Universali.

Silagadze, Ap’olon 2018. Kartuli mq’ari salekso pormebis aghmosavluri ts'q'aroebi. In: Evrop'uli da aghmosavluri mq'ari salekso pormebi kartul p’oeziashi, I. Tbilisi: Meridiani, 9-31.

Ts’ereteli, Giorgi 1973. Met’ri da ritma “vepkhist'q’aosanshi”. Tbilisi: Metsniereba. 